\title{
Pump Down Rate for SRF Cavities
}

\author{
M. Kuchnir \\ Fermi National Accelerator Laboratory \\ P.O. Box 500, Batavia, Illinois 60510 \\ J. Knobloch \\ Laboratory of Nuclear Studies \\ Cornell University
}

February 1992 


\section{Disclaimer}

This report was prepared as an account of work sponsored by an agency of the United States Government. Neither the United States Government nor any agency thereof, nor any of their employees, makes any warranty, express or implied, or assumes any legal liability or responsibility for the accuracy, completeness, or usefulness of any information, apparatus, product, or process disclosed, or represents that its use would not infringe privately owned rights. Reference herein to any specific commercial product, process, or service by trade name, trademark, manufacturer, or otherwise, does not necessarily constitute or imply its endorsement, recommendation, or favoring by the United States Government or any agency thereof. The views and opinions of authors expressed herein do not necessarily state or reflect those of the United States Government or any agency thereof. 


\title{
Pump Down Rate for SRF Cavities
}

\author{
M. Kuchnir \\ Fermi National Accelerator Laboratory \\ and \\ Jens Knobloch \\ Laboratory of Nuclear Studies of Cornell Universty \\ February 15, 1992
}

\section{INTRODUCTION}

The problem presently limiting niobium Superconducting Radio Frequency (SRF) cavities from reaching their potential high $Q$ is electron field emission from the walls. There is strong evidence that this field emission is enhanced by microscopic dust particles deposited on the surface. Clean room techniques are therefore used in the preparation of these cavities. One of these techniques that should be implemented is to avoid aerosols (i.e. particles floating in the air) from being deposited on the cavity inner walls when air is evacuated from the cavity.

The size of aerosols present in clean-room environments vary from atomic (electrons, ions, foreign molecules) to a few microns. The class of a clean room is defined (in the US at least) as the total number of particles per cubic foot greater than 0.5 microns in size. Water molecules in the air and particles ( 0.5 microns ("fines") therefore do not count, although such particles can enhance field emission when deposited on the surface.

The adiabatic expansion of the air as it is rapidly pumped out of the cavity causes it to cool condensing water molecules around nucleation sites (particles, fines, ions) causing them not just to grow, becoming countable, but also to stick to the walls. Turbulence is instrumental in depositing them on the surface by speeding up the growth of these water coated particles and increasing their chance of hitting (and therefore sticking to) the wall before they are evacuated out of the cavity.

So control of the pumping speed when evacuating the clean-room air from the cavity is a relevant technique along with other pre-evacuation [1] ones like, dehumidifying the air, using an electrostatic particle precipitator, flushing with dry nitrogen, heating the cavity and perhaps others. Although some of these techniques seem mutually exclusive or reduntant they should be considered independently since in each case the logistics of cleanliness might impose constraints in their use.

This note is about calculations aimed at quantifying adequate pumping speeds of evacuation of normally humid clean-room air from typical SRF cavities. The subject is of high relevance to the semicondutor industry, where the yield of VLSI (Very Large Scale Integration) chip production is affected by micron size particles which may cause fatal defects to their micron and sub-micron features. The recent availability of particle counters capable of operating in vacuum has stimulated measurenents at reduced pressures in this subject [2-6].

The two physical phenomena of relevance here are turbulence and condensation, each yielding a limiting value for the pumpdown speed. 


\section{TURBULENCE}

A fluid is in turbulent flow whenever its Reynolds Number (Re) is larger than 2000 and in laminar flow when Re $<100$. The definition of Re is:

$$
R e=\frac{V \cdot D \cdot \text { rho }}{m u}
$$

$$
\text { where: } \begin{aligned}
& v=\text { velocity } \quad(\mathrm{m} / \mathrm{s}) \\
D & =\text { characteristic } \\
& \text { dimension }(\mathrm{m}) \\
& \text { rho }=\text { density } \quad(\mathrm{kg} / \mathrm{m} 3) \\
\mathrm{mu} & =\text { viscosity } \quad(\mathrm{kg} /(\mathrm{m} . \mathrm{s}))
\end{aligned}
$$

In order to apply this to a cavity being evacuated by manual control of a valve, using a Hallace Tiernam pressure gauge and a watch, we have to write $\checkmark$ and rho in terms of the pressure $P$ and temperature $T$ of the air in the cavity as well as time $t$.

From the equation of state of a perfect gas:

$$
P \cdot V_{0}=n \cdot R \cdot T
$$

we obtain

$$
\text { rho }=\frac{n \cdot w}{V_{0}}=\frac{w \cdot P \cdot V_{0}}{V_{0} \cdot R \cdot T}=\frac{w \cdot P}{R \cdot T}
$$

where: $n=$ number of moles of air in the cavity

$$
\begin{aligned}
& w=\text { molecular weight of air } \\
& V_{0}=\text { volume of the cavity }
\end{aligned}
$$$$
R=\text { gas constant }
$$

The pumping speed is also given by:

$$
\begin{aligned}
& \dot{v}=0.25 \cdot \mathrm{pi} \cdot \mathrm{D}^{2} \cdot \mathrm{v} \text { where } \mathrm{pi}=3.14159 \\
& v_{0} \cdot \dot{\mathrm{p}}=-\dot{v} \cdot \mathrm{p} \quad \text { therefore } \dot{v}=-\frac{V_{0} \cdot \dot{p}}{\mathrm{p}}
\end{aligned}
$$

When treating condensation it will be important to consider the change in temperature. Here we will cosider T constant, which is a good approximation if the pumping speed is low and there is time for the heat flowing from the walls to keep the process isothermal. Therefore

$$
v=-\frac{4}{\mathrm{pi} \cdot \mathrm{D}^{2}} \quad \frac{V_{0} \cdot \dot{\mathrm{P}}}{\mathrm{P}}
$$

So in terms of the parameters of the air in the cavity the Reynolds Number can be written as:

$$
R_{e}=\frac{4 \cdot \frac{w \cdot V_{0} \cdot \dot{p}}{p i \cdot R \cdot m u \cdot D \cdot T}}{p^{2} \cdot R}
$$


To insure laminar flow evacuation we should keep Re $<100$ or

$$
|\dot{P}|<\frac{100 \cdot \mathrm{pi}}{4} \cdot \mathrm{R} \cdot \frac{\mathrm{mu}}{\mathrm{w}} \cdot \frac{\mathrm{D}}{\mathrm{V}_{0}} \cdot \mathrm{T}
$$

$$
\begin{aligned}
& \text { Using SI units: } \quad R=8.31 \mathrm{~J} / \text { (mole.K) } \\
& \text { for air: } \quad w=.029 \mathrm{~kg} / \mathrm{mole} \\
& \mathrm{mu}=18.2 \mathrm{E}-6 \mathrm{~kg} /(\mathrm{m} . \mathrm{s}) \quad \text { (which holds down to } 1 \text { torr) } \\
& \mathrm{T}=297 \mathrm{~K} \quad \text { (a typical room temperature) } \\
& |\dot{P}|<122 . \stackrel{D}{V_{0}} \quad \mathrm{~Pa} / \mathrm{s} \quad \begin{array}{l}
\text { where } D \text { and } V_{0} \text { are in meters } \\
\text { and cubic meters respectively }
\end{array}
\end{aligned}
$$

or

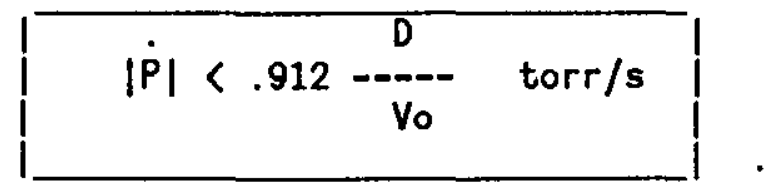

\section{CONDENSATION}

Ridding the air of aerosols, via condensation, was a routine process in priming a Wilson cloud chamber for detection of ionizing particle tracks. of course, then the physicists did not care about the particles sticking to the walls. Next follows a tutorial on humidity.

The relative humidity of the air (RH) can best be defined in the following way: At a given temperature and pressure a certain mass, $m A$, of dry air can absorb at most a mass, milmax, of water vapor without forming droplets regardless of aerosols and turbulence. The ratio mWmax/mA corresponds to saturation of the air or $\mathrm{RH}=100 \%$. For a mass $\operatorname{mW}<\mathrm{mWmax}$ we have:

$$
\mathrm{RH}=100 \frac{\mathrm{mW}}{\text { milmax }}
$$

It is possible to have $m W>$ mWmax in quiet (non turbulent) and perfectly clean air (no particles, no ions etc). The saturation ratio,

$$
S=\frac{\text { mW' }}{\text { mW'max }}
$$

can have values as large as 8 .

The condensation process is called homogeneous when the nucleation sites are clusters of water molecules. The critical saturation ratio, Sc, at which homogeneous condensation occurs has usually values between 3 and 8 .

Condensation nucleated by positive ions has Sc around 6 and by negative ions around 4. When the nucleating sites are particles of size ranging from $2 \mathrm{~nm}$ to larger than .1 microns the process is called heterogeneous condensation and Sc has a value between 1 and 3 . The saturation $\mathrm{mWmax} / \mathrm{mA}$ is a function of temperature, increasing with it. This type of data constitute the so called psychrometric tables.

Since the "rediscovery" paper of Degang Chen and Susan Hackwood [2] most papers related to the semiconductor industry have dealt with this subject with specific goals in mind. One of them, [6], however, provides an algorithm for solving our problem. It is published in a trade magazine (free subscription to practitioners in the business) and it is based on the Ph.D. Thesis in Mechanical Engineering at University of Minnesota of its first author J. Zhao (1990). Without having read this thesis we limit ourselves 
Characterising the geometry of the vacuum chamber, the pumping system, and the gas in it respectively by the parameters ksi, tau and omega, given below, he defines the Zhao's dimensionless number

$$
Z=\frac{\text { omega . tau }}{k s i}
$$

that describes the evolution of the thermodynamic states taken by the system from close to adiabatic $(Z=0)$ to essentially isothermal $(Z=$ infinite). Properly converted to units used with figure 1 the parameters are:

$$
\mathrm{ksi}=100 \begin{gathered}
V_{0} \\
\text { So }
\end{gathered} \quad \operatorname{tau}=V_{0} / \dot{V}=\mathrm{P} / \dot{\mathrm{P}} \quad \text { omega }=(\mathrm{g} \cdot \mathrm{alpha} / \mathrm{Pr})^{1 / 3}
$$

where So is the area of the cavity in square meters, $g$ is the gravitational constant, alpha is the air thermal diffusion coefficient at the initial pressure and temperature and $\mathrm{Pr}$ is the air Prandtl number. For 760 torr and $293 \mathrm{~K}$ the numerical value of omega to be used in these formulas is 6.73 .

The maximum saturation ratio, Smax, that occurs in a pumpdown is a function of $\mathrm{RH}$ and $Z$, and reproduced in figure 1 . The algorithm proceeds in the following way: For a given $R H$ figure 1 is used to determine $Z$ for heterogeneous condensation using the $\operatorname{Smax}=1$ curve. This is the minimum $Z$ that can be used and it leads to the inequality

$$
|\dot{P}|<51.1 \frac{\text { So }}{V_{0} . Z}
$$

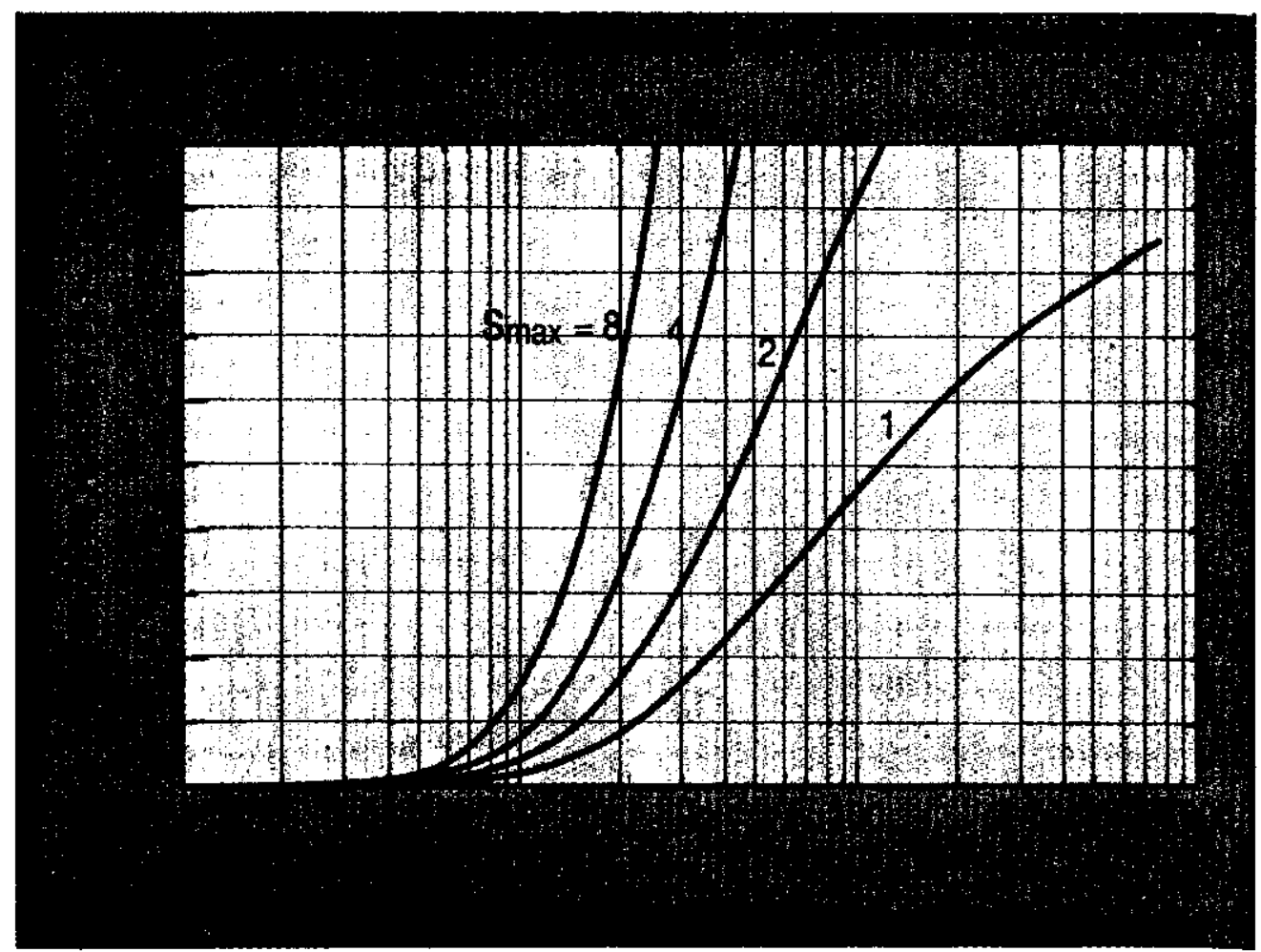

Figure 1. Curves of Smax in the RH vs $Z$ plane 
Table I presents rough estimates of parameters for 4 typical cavities and the calculated pumpdown rates that the above formulas yield for laminar flow (1st formula) and Zhao's algorithm for air initially at $293 \mathrm{~K}$, 760 torr and relative humidities of $80 \%$ and $20 \%$.

TABLE I:

\begin{tabular}{|c|c|c|c|c|c|c|}
\hline CAVITY & $\begin{array}{l}\text { Cavity } \\
\text { Vo } \\
\text { (m3) }\end{array}$ & $\begin{array}{l}\text { Paramet } \\
\text { So } \\
\text { (m2) }\end{array}$ & $\begin{array}{c}\text { ers } \\
0 \\
(m)\end{array}$ & $\begin{array}{l}\text { PUMPING } \\
\text { l ami nar } \\
\text { flow }\end{array}$ & $\begin{array}{l}\text { RATE } \\
\text { RH = } \\
80 \%\end{array}$ & $\begin{array}{c}\text { (torr/s) } \\
\mathrm{RH}= \\
20 \%\end{array}$ \\
\hline $\begin{array}{l}\text { B Factory } \\
\text { (1st test) }\end{array}$ & $91 . \mathrm{E}-3$ & 2.2 & .027 & .27 & 2.2 & 33. \\
\hline $\begin{array}{l}\text { Mushroom } \\
\text { Mark } 1\end{array}$ & $.21 E-3$ & $25 \cdot E-3$ & 35.E-3 & 150 & 11. & 170 \\
\hline $\begin{array}{l}\text { Mushroom } \\
\text { Mark } 4\end{array}$ & $.26 \mathrm{E}-3$ & 51.E-3 & $1.2 \mathrm{E}-3$ & 4.1 & 18. & 280 \\
\hline $\begin{array}{l}\text { L. Band } \\
\text { LE1-28 }\end{array}$ & $2.8 E-3$ & .15 & .07 & 23 . & 5.0 & 76. \\
\hline
\end{tabular}

\section{CONCLUSION}

The pumping rates calculated above can be readily achieved by manual control and a needle valve bypassing a typical gate valve. The pump rate most demanding on the operator is .27 torr $/ \mathrm{s}$. This low value is needed to prevent turbulence near the iris coupling the waveguide to the cavity in the pump out scheme used for the first test of the B_Factory cell.

\section{ACKNOMLEDGMENT}

The authors thank $\mathrm{Dr}$. H. Padansee for suggesting the problem, Dr. H. F. Dylla for calling attention to the literature on the subject and the hospitality of the Laboratory of Nuclear Studies of Cornell Universty. This work was sponsored by the Fermilab-Cornell collaboration for the TESLA project.

\section{REFERENCES}

[1] B.D. McDaniel, private communication

[2] Degang Chen and Susan Hackwood, J. Vac. Sci. Technol., vol. A8, p.933 (1989)

[3] Degang Chen et al, J. Vac. Sci. Technol., vol. A7, p. 3105 (1989)

[4] J.J. Wu et al, J. Vac. Sci. Technol., vol. A8, p. 1961 (1990)

[5] J.F. D'Hanlon and J. Shieh, J. Vac. Sci. Technol., vol. A9, p. 2802 (1991)

[6] J. Zhao et al, Solid State Technology, vol. 33, p. 85 (Sep 1990) 
Characterising the geometry of the vacuum chamber, the pumping system, and the gas in it respectively by the parameters ksi, tau and omega, given below, he defines the Zhao's dimensionless number

$$
Z=\frac{\text { omega . tau }}{\text { ksi }}
$$

that describes the evolution of the thermodynamic states taken by the system from close to adiabatic $(Z=0)$ to essentially isothermal ( $Z=$ infinite). Properly converted to units used with figure 1 the parameters are:

$$
\text { ksi }=100 \text { - } \begin{gathered}
\text { Vo } \\
\text { So }
\end{gathered} \quad \text { tau }=V_{0} / \dot{V}=P / \dot{P} \quad \text { omega }=(\mathrm{g} \cdot \text { alpha } / \mathrm{Pr})^{1 / 3}
$$

where So is the area of the cavity in square meters, $g$ is the gravitational constant, alpha is the air thermal diffusion coefficient at the initial pressure and temperature and $\mathrm{Pr}$ is the air Prandtl number. For 760 torr and $293 \mathrm{~K}$ the numerical value of omega to be used in these formulas is 6.73 .

The maximum saturation ratio, Smax, that occurs in a pumpdown is a function of $\mathrm{RH}$ and $Z$, and reproduced in figure 1 . The algorithm proceeds in the following way: For a given RH figure 1 is used to determine $Z$ for heterogeneous condensation using the $S \max =1$ curve. This is the minimum $Z$ that can be used and it leads to the inequality

$$
|\dot{P}|<51.1 \frac{\text { So }}{V_{0} . Z}
$$

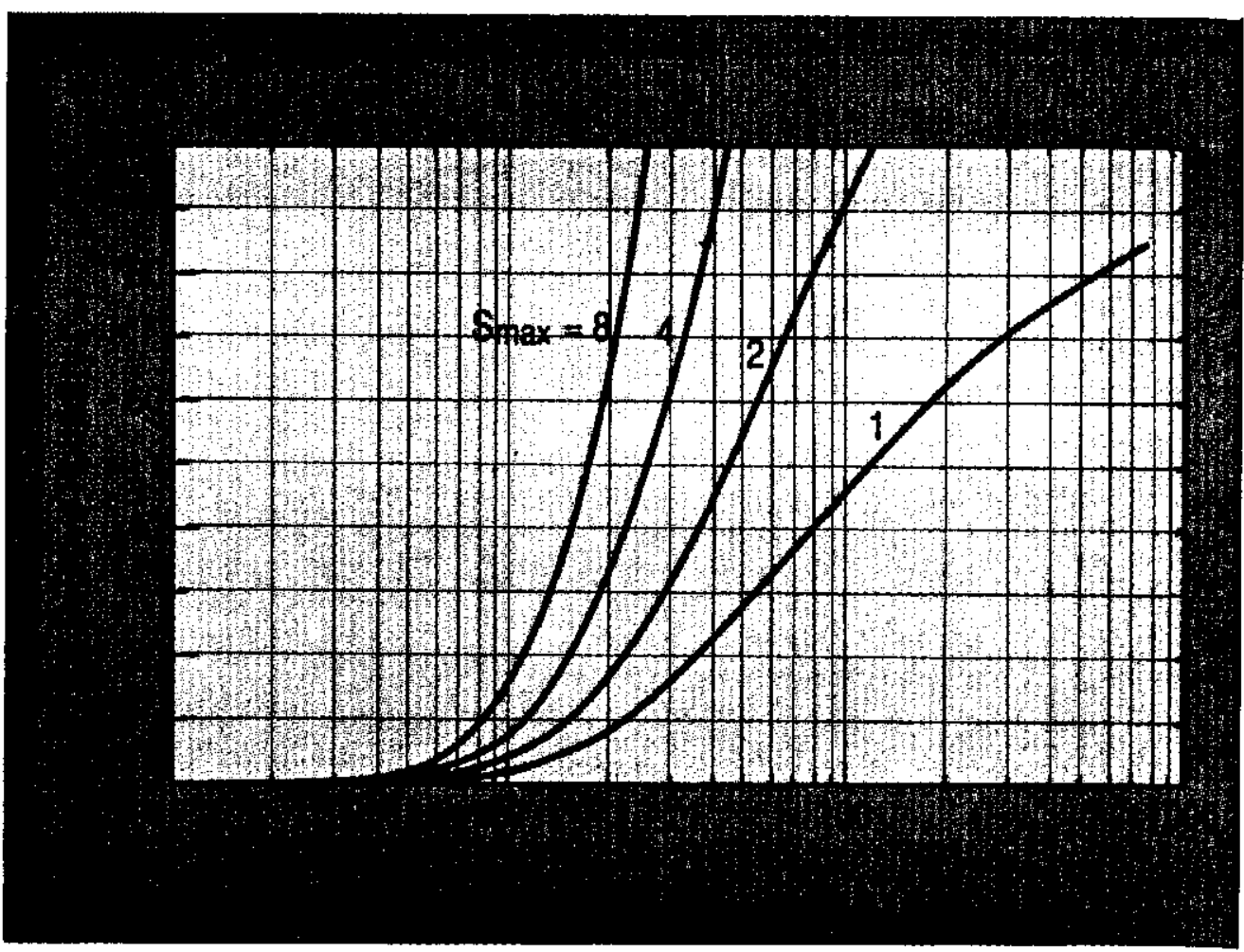

Figure 1. Curves of Smax in the RH vs $Z$ plane 